\title{
CLASSIFICAÇÃO CLIMÁTICA PARA MINAS GERAIS POR MEIO DO MÉTODO DE AGRUPAMENTO NÃO HIERÁRQUICO DE K-MEANS
}

\author{
Lilian Aline Machado ${ }^{1}$
}

\begin{abstract}
Resumo
Este trabalho teve como objetivo obter uma classificação de tipos climáticos para o estado de Minas Gerais. Como principal apoio metodológico foi utilizada a análise multivariada, voltada ao agrupamento de dados em grupos nos quais os dados apresentam a maior semelhança entre si dentro dos grupos, e a maior diferença possível entre os grupos. O método estatístico utilizado foi o cluster k-means. A base de dados compreendeu valores diários de temperatura média compensada, temperatura máxima e mínina, precipitação, evaporação e umidade relativa do ar de 26 estações meteorológicas no período de 1981-2011. Foram obtidas três classes climáticas relacionadas ao comportamento térmico e pluviométrico do estado.
\end{abstract}

Palavras-chave:análise multivariada, classificação climática, k-means cluster

\begin{abstract}
This study aimed to obtain a climatic classification for the state of Minas Gerais. As the main methodological support was used multivariate analysis, to grouping data into groups in which the data show the highest resemblance to each other within the groups, and the largest possible difference between the groups. The statistical method used was the cluster k-means. The database comprised daily values of average temperature compensated, maximum temperature and minina, precipitation, evaporation and relative humidity of 26 weather stations in the 1981-2011 period. Three climatic classes related to rainfall and thermal behavior of the state were obtained.
\end{abstract}

Key-words:multivariate analysis; climatic classification, k-means cluster

1 Mestrando do Programa de Pós-Graduação em Geografia da Universidade Federal de Minas Gerais (lilian.aline.machado@hotmail.com) 


\section{1- INTRODUÇÃO}

A compreensão do comportamento climático de uma determinada localidade é fundamental como subsídio ao planejamento territorial e para fins de manejo de recursos naturais, uma vez que ao clima estão atreladas condições propícias ou não à exploração de recursos e ao desenvolvimento das atividades humanas. Dessa forma, torna-se necessária a busca, evolução e adaptação de métodos de classificação capazes de sintetizar e agrupar características similares de comportamento das variáveis meteorológicas por meio de critérios definidos de acordo com o propósito da classificação (FERREIRA, 2012).

Com a finalidade de subsidiar a compreensão dos climas que se configuram sobre a superfície do planeta, a climatologia depara-se com o desafio de manipular extensas massas de dados meteorológicos disponíveis a fim de se produzir sínteses dos tipos climáticos. No Brasil, ainda que não haja uma quantidade satisfatória de estações meteorológicas oficiais do Instituto Nacional de Meteorologia (INMET) para cobrir o território nacional, e que haja extensas falhas de dados e diferentes datas de operação das estações, um grande volume de dados se encontra disponível ${ }^{2}$ para os pesquisadores do clima.

No intuito de facilitar a manipulação de dados referentes a variáveis meteorológicas múltiplas, o pesquisador pode recorrer à estatística utilizando-se dos métodos de análise multivariada. $\mathrm{O}$ termo "análise multivariada" é relativo a um grande número de métodos e técnicas estatísticas que manipulam, de maneira simultânea, todas as variáveis envolvidas na interpretação teórica do conjunto de dados obtidos (NETO, 2004).

Existem diversos métodos de análise multivariada, os quais apresentam finalidades diversas entre si. Este trabalho tem como objetivo a classificação de grupos de comportamento de determinadas variáveis climáticas estatisticamente semelhantes no estado de Minas Gerais, a fim de se obter uma classificação de tipos climáticos. Dessa forma, pretende-se verificar como as amostras se relacionam, ou seja, o quanto as variáveis meteorológicas utilizadas no trabalho são semelhantes entre si formando grupos de comportamentos diferentes, utilizando-se um método de análise multivariada adequado ao objetivo do trabalho.

\footnotetext{
${ }^{2}$ Dados disponíveis em: <http://www.inmet.gov.br/portal/index.php?r=bdmep/bdmep>.

Cadernos do Leste 


\section{2- FUNDAMENTAÇÃO TEÓRICA E BASES CONCEITUAIS}

\subsection{A análise de cluster e o método K-means}

Classificar elementos em grupos de acordo com suas características é uma necessidade inerente a diversas áreas do conhecimento como forma de esquematizar sínteses dos objetos de estudo aos quais se remetem cada uma dessas áreas. No entanto, quando o estudo de tais objetos requer a manipulação de uma base de dados volumosa a análise de combinações de grupos é dificultada. Para auxiliar na formação dos agrupamentos é necessário, então, recorrer a métodos estatísticos que facilitem a manipulação do extenso volume de dados. A análise de cluster, ou análise de agrupamento, pode ser uma saída para tal problema, sendo ela um método que busca agrupar elementos baseando-se na similaridade entre eles.

A análise de cluster pode ser realizada por meio de dois grupos de métodos: os métodos hierárquicos e os métodos não-hierárquicos. I.S.A. (2009) define os métodos hierárquicos como sendo aqueles em que o agrupamento em classes se procede por etapas determinando, em geral, a partir de $\mathrm{n}$ subgrupos, sucessivas fusões de subgrupos considerados mais "semelhantes". Quanto aos métodos nãohierárquicos, faz-se uma classificação inicial de $\mathrm{n}$ indivíduos em $\mathrm{k}$ classes. $\mathrm{O}$ número de classes que se pretende constituir deve ser fixado inicialmente. Assim, por meio de transferências de indivíduos de uma classe para outra, ou de associações dos indivíduos à características médias das classes, determinase uma classificação na qual aproxima-se da homogeneidade dentro dos grupos e da heterogeneidade entre eles (I.S.A., 2009).

Neste trabalho optou-se por adotar o método de classificação não-hierárquico k-Means Cluster, o qual permite observar o comportamento assintótico pertinente dos dados avaliados, com o objetivo de estabelecer algum tipo de classificação de acordo com as kmédias³ da amostra (MACQUEEN, 1967). Também chamado de Quick cluster, o método de k-means foi desenvolvido em uma época em que se necessitava de softwares que manipulassem extensas bases de dados de maneira rápida e que não exigisse dos computadores configurações tão avançadas quanto as que existem atualmente.

André et al. (2008) desenvolveram um trabalho com o objetivo de estabelecer as regiões pluviometricamente homogêneas no estado do Rio de Janeiro. Os autores adotaram a análise nãohierárquica pelo método k-means para definir os agrupamentos homogêneos de precipitação no estado do Rio de Janeiro, utilizando dados de estações meteorológicas oficiais do Instituto Nacional de Meteorologia (INMET) e da Agência Nacional de Águas (ANA) de 1971 a 2000. Os autores definiram seis classes pluviométricas estatisticamente homogêneas, as quais se relacionaram com a altitude,

\footnotetext{
${ }^{3}$ As K-médias consistem nas médias de um número k de classes pré-definido de acordo com os critérios de análise adotados pelo operador da estatística. Em outras palavras, seriam as médias de cada cluster gerado.

Cadernos do Leste

Artigos Cientificos

Belo Horizonte, Dez. Vol.14, n¹4, 2014
} 
topografia, conformação da costa e a influência sofrida pela alta umidade proveniente do oceano. Nas regiões de menor precipitação, há uma grande baixada a sotavento da Serra do Mar, o que favorece a compreensão na baixa troposfera por ocasião das penetrações de escoamento de sudoeste.

Dourado et al. (2012) realizou estudo semelhante ao de André et al. (2008) para o estado da Bahia. No entanto, os autores definiram quatro classes para a aplicação do método k-means. Já Guedes et al. (2010), em oposição ao autores já citados, utilizaram a análise hierárquica para definir o número de classes homogêneas de precipitação no estado do Piauí, identificando quatro classes. Becker et al. (1992) também utilizaram a análise hierárquica para regionalizar a precipitação e a temperatura no estado do Rio Grande do Sul. Os autores aplicaram um cluster para cada variável distinguindo o corte para o número de classes homogêneas com base no maior saldo da soma total do quadrado dos desvios de cada ponto com relação ao centro de gravidade do grupo. Sendo assim, distinguiram cinco classes de temperatura e dois cortes para a precipitação, um com cinco grupos e outro com dois grupos.

\subsection{Métodos de classificação climática}

A finalidade de qualquer sistema de classificação climática (SCC) é obter um arranjo eficiente de informações a respeito do comportamento atmosférico médio sobre determinada superfície de forma simplificada e generalizada (BARRY e CHORLEY, 2013). Mendonça e Danni-Oliveira (2007) salientam que, embora não haja na superfície terrestre climas idênticos, a classificação dos tipos climáticos é uma tarefa geograficamente útil já que leva a uma compreensão da realidade espacial, ainda que resulte em uma certa redução.

Estabelecer uma classificação climática é um trabalho complexo, já que as variáveis escolhidas para a classificação não compreendem o clima em todas as suas especificidades, dinâmica e complexidade. A escolha das variáveis utilizadas no SCC depende dos objetivos da aplicação da mesma e por isso qualquer classificação servirá satisfatoriamente somente a alguns propósitos (MENDONÇA e DANI-OLIVEIRA, 2007; BARRY e CHORLEY, 2013).

Existem diversos métodos de classificação climática, os quais atendem a distintos objetivos. De maneira geral eles podem apresentar uma abordagem genética ou empírica para a classificação. A primeira abordagem está baseada nos controles climáticos, sendo estes, os fatores que determinam ou causam os diferentes climas, como as massas de ar ou os centros de ação (AYOADE, 1986). Já na segunda abordagem a classificação está baseada nos próprios elementos climáticos mensurados e tratados estatisticamente ou em seus efeitos sobre outros fenômenos como a vegetação (AYOADE, 1986). 
A tabela 1 apresenta alguns exemplos de sistemas de classificação climática e suas principais características.

Tabela 1: Sistemas de classificação climática e suas principais características

\begin{tabular}{|c|c|c|c|c|}
\hline $\begin{array}{c}\text { SIATEMAS DE } \\
\text { CLASSIFICAÇÁOO CLIMÁTICA }\end{array}$ & ABORDAGEM & PRINCIPAIS CARACTERÍSTICAS & TIPOS CLIMÁTICOS & SUBTIPOS CLIMÁtICOS \\
\hline Thornthwaite e Matter (1995) & Empírica & $\begin{array}{l}\text { Está fundamentado no conceito de balanço hídrico proposta por } \\
\text { Thornthwaite em } 1948 \text { e aperfeiçoada pelo próprio juntamente } \\
\text { com Matter em 1955. Este método } \\
\text { calcula a disponibilidade de água armazenada no solo em função } \\
\text { da cobertura vegetal e objetiva determinar o saldo } \\
\text { hídrico do sistema, excedente ou deficiente, contabilizando a } \\
\text { entrada de água via precipitação e a saída pela } \\
\text { evapotranspiração potencial (ETP ) e a evapotranspiração real } \\
\text { (ETR). Os tipos climáticos ou províncias são } \\
\text { classificados quanto ao grau de umidade e quanto à } \\
\text { eficiência térmica e delimitados a partir das categorias } \\
\text { estabelecidas pelos valores do índice de umidade e da } \\
\text { evapotranspiração potencial. }\end{array}$ & \multicolumn{2}{|c|}{$\begin{array}{l}\text { Os tipos e subtipos climáticos são representados por letras } \\
\text { maiúsculas e minúsculas relacionadas às } \\
\text { características térmicas e hígricas do clima. A chave de } \\
\text { classificação é apresentada no Anexo I. }\end{array}$} \\
\hline Köppen (1936) & Empírica & $\begin{array}{l}\text { A classificação utiliza de critérios de temperatura e aridez, } \\
\text { fixando limites ajustados à distribuição dos tipos de vegetação. }\end{array}$ & \multicolumn{2}{|c|}{$\begin{array}{l}\text { O modelo de Köppen compreende um conjunto de letras } \\
\text { maiúsculas e minúsculas para designar os grandes grupos } \\
\text { climáticos, os subgrupos e as } \\
\text { subdivisões quando há características especiais sazonais. A } \\
\text { chave de classificação encontra-se no Anexo I. }\end{array}$} \\
\hline Strahler (1969) & Genética & $\begin{array}{c}\text { A classificação climática é baseada nos centros de ação e massas } \\
\text { de ar que atuam sobre o território. O clima é classificado } \\
\text { segundo os componentes de sua gênese e dinâmica. }\end{array}$ & $\begin{array}{c}\text { climas das latitudes baixas } \\
\text { (controlados pelas massas } \\
\text { de ar } \\
\text { equatoriais e tropicais) } \\
\text { climas das latitudes } \\
\text { médias (controlados pelas } \\
\text { massas de ar } \\
\text { tropicais e polares) } \\
\\
\text { Climas das latitudes altas } \\
\text { (controlados pelas } \\
\text { massas de ar polar e } \\
\text { ártica) }\end{array}$ & \begin{tabular}{|} 
Equatorial úmido / \\
Litorâneo com ventos alíseos / \\
Desértico tropical e de estepe / \\
Desértico da \\
costa ocidental / Tropical \\
seco-úmido \\
Subtropical úmido / \\
Marítimo da costa ocidental \\
/ Mediterrâneo / Desértico e \\
de estepe de latitude média / \\
Continental úmido \\
\\
Continental subártico / \\
Marítimo subártico / Tundra \\
/ Calota de gelo / Climas de \\
terras altas
\end{tabular} \\
\hline Flohn (1950) & Genética & $\begin{array}{l}\text { As principais categorias baseiam-se nos cinturões globais de } \\
\text { ventos e na sazonalidade da precipitação. }\end{array}$ & $\begin{array}{c}\text { Zona equatorial de ventos } \\
\text { de oeste } \\
\text { Zona tropical, alíseos de } \\
\text { inverno } \\
\text { Zona subtropical seca } \\
\text { Zona subtropical de } \\
\text { chuvas de inverno } \\
\text { Zona extratopical de } \\
\text { ventos de oeste } \\
\text { Zona subpolar e zona } \\
\text { boreal } \\
\text { Zona polar }\end{array}$ & $\begin{array}{l}- \\
- \\
- \\
- \\
- \\
- \\
- \\
-\end{array}$ \\
\hline
\end{tabular}

Fonte: Organizado pela autora a partir de Mendonça e Danni-Oliveira (2007) e Barry e Chorley (2013).

Nimer (1979) propôs uma classificação climática para o Brasil a qual resultou nomapa de climas publicado pelo Instituto Brasileiro de Geografia em 1978 e adaptado recentemente (IBGE, 2002). Nimer, apoiado na crença de que a integração de métodos tradicionais e dinâmicos exprime mais do que razoavelmente as complexas relações entre os fatores ecológicos do território brasileiro, baseou-se em três sistemas de classificação climática. O primeiro sistema compreende a identificação dos padrões de circulação atmosférica e seu fator genético-dinâmico que controla o regime climático anual, Cadernos do Leste 
exprimindo os climas zonais. O segundo sistema delimita as regiões térmicas, com base em índices elaborados por diferentes autores. Em Minas Gerais três classes pertencentes a esse sistema abrangem o território, sendo elas: regiões de clima Quente (média em todos os meses do ano $>18^{\circ} \mathrm{C}$ ); regiões de clima Subquente (média entre 15 e $18^{\circ} \mathrm{C}$ em pelo menos um mês), e; regiões de clima Mesotérmico Brando (média entre 10 e $15^{\circ} \mathrm{C}$ ).

Por fim, o terceiro sistema define as regiões quanto à umidade, baseado na existência ou não de seca e no comprimento médio da estação seca. A definição de seca é de Gaussen e Bagnouls, os quais consideram seco o mês no qual a média dos totais mensais de precipitação em milímetros (ou em cm) é igual ou inferior ao dobro da temperatura média em graus Celsius, convertidos em milímetros ou centímetros. A visualização dos meses secos pode ser feita por meio de um gráfico ombrotérmico, no qual é representada a relação matemática mencionada entre temperatura e precipitação.

Álvares et al. (2013), utilizando as prerrogativas do sistemas de classificação de Köppen (1936) geraram um mapa da classificação climática para o país com resolução de 1hectare. Os autores programaram um algoritmo de classificação utilizando procedimentos de geoprocessamento utilizando dados de temperatura e precipitação.

Ferreira (2012) propôs uma classificação de unidades climáticas para a bacia hidrográfica do rio Paraibuna $(\mathrm{MG} / \mathrm{RJ})$ por meio da análise de componentes principais e da análise de agrupamentos nãohierárquica pelo método Fuzzy-cluster. A autora optou por utilizar as variáveis temperatura média diária, precipitação e deficiência e excedente hídricos, as quais consistiram estatisticamente nas mais importantes para a separação das classes. Após a aplicação do método fuzzy foi estabelecido um quadro síntese das situações de tempo na bacia, a partir do qual foram definidas cinco unidades climáticas distintas. Nessas unidades o comportamento térmico-hígrico esteve bastante atrelado à condições do relevo local.

\section{3- MATERIAIS E MÉTODOS}

As etapa de realização deste trabalho estão ilustradas na figura 1. Primeiramente, partiu-se da revisão bibliográfica no intuito de levantar os métodos estatísticos de agrupamento e suas aplicações e os sistemas e métodos de classificação climática a fim de se estabelecer bases para a aplicação do trabalho.

\footnotetext{
4 KÖPPEN, W. Das geographische System der Klimate. In: KÖPPEN, W.; GEIGER, R. (Eds.). Handbuch der Klimatologie. - Gebrüder Bornträger, Berlin, 1, p. 1-44, part C.
}

Cadernos do Leste

Artigos Cientificos

Belo Horizonte, Dez. Vol.14, n¹4, 2014 


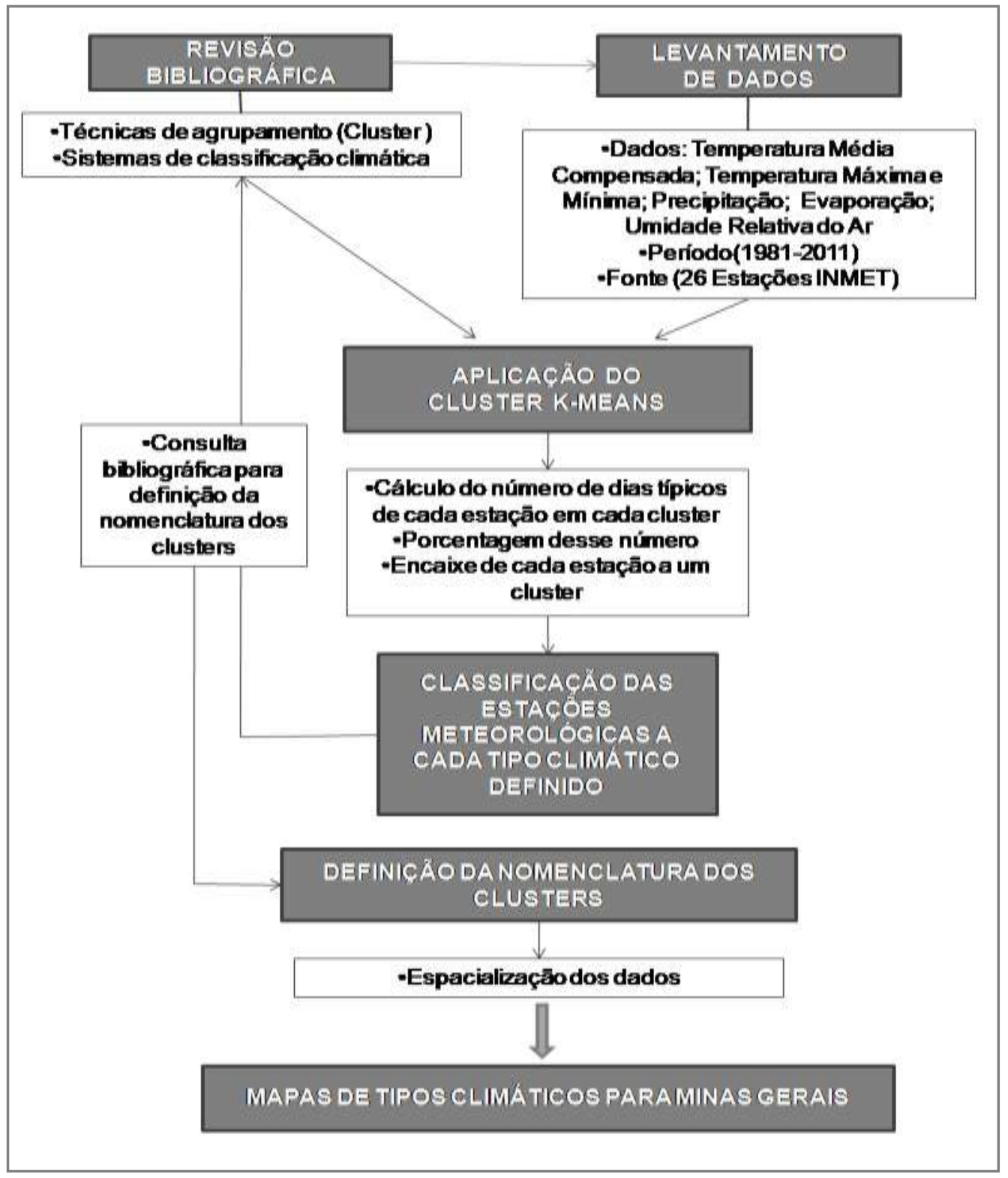

FIGURA 1: Etapas de elaboração do trabalho.

Em seguida foram levantados dados diários de temperatura média compensada, temperatura máxima e mínima, precipitação, evaporação e umidade relativa do ar de 26 estações meteorológicas do Instituto Nacional de Meteorologia (INMET) localizadas no estado de Minas Gerais (FIG. 2). Os dados foram coletados do banco de dados do INMET $^{5}$. A escolha das estações obedeceu o critério de haver, em cada uma delas, pelo menos 30 anos de dados disponíveis. O período coincidente de dados entre as 26 estações definiu o período de análise dos dados coletados, sendo ele de 1981 a 2011.

\footnotetext{
${ }^{5}$ Dados disponíveis para download em: <http://www.inmet.gov.br/portal/index.php?r=bdmep/bdmep >..

Cadernos do Leste 


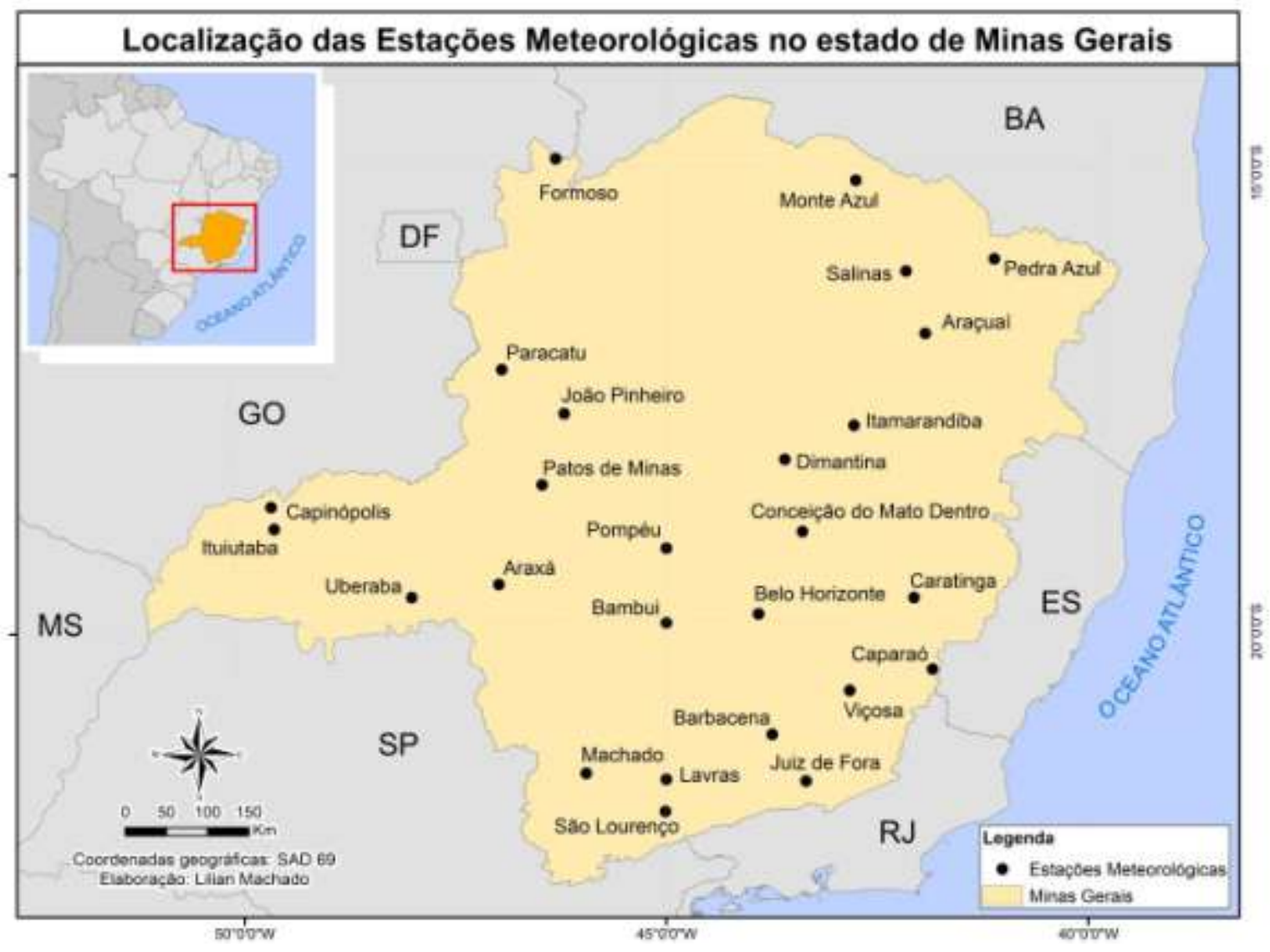

FIGURA 2: Localização das estações meteorológicas do INMET utilizadas no trabalho.

Após a escolha da série de dados foi aplicado o método de agrupamento k-means no software SPSS (Statistical Package for the Social Sciences ). O método de k-means, funciona da seguinte maneira: (a) primeiramente deve-se escolher um número de clusters que se deseja obter; (b) quando inicia-se o procedimento, o software arbitra cluster iniciais; (c) com a aplicação do algorítimo, as médias de cluster cluster se alteram conforme são rodadas novas iterações até que haja uma convergência dos resultados, ou seja, quando o algorítimo converge para um ponto em que as atribuições de cada cluster não se alteram de uma iteração para a próxima.

O método k-means, aplicado no software SPSS, utiliza a distância euclidiana das médias para gerar as médias centrais de cada cluster. Neste trabalho foi iniciado o método com um número de iterações igual a 100. Porém, houve convergência dos resultados ao se rodar 68 iterações. Primeiramente foram escolhidos cinco clusters para a aplicação baseandose no experimento de Ferreira (2012). No entanto, dos cinco clusters definidos, somente em três se encaixaram os dados coletados. Sendo assim, foi realizado um novo procedimento kmeans com quatro clusters, embora, ainda assim, somente três clusters corresponderam ao comportamento dos dados utilizados. Os valores de cada 
cluster estão representados na tabela 2. Considerando que foram utilizados dados diários, cada cluster representa um comportamento diário típico.

Tabela 2: Valores das variáveis analisadas para cada cluster gerado

\begin{tabular}{l|c|c|c|c}
\hline \multirow{2}{*}{\multicolumn{1}{c|}{ VARIÁ VEL }} & \multicolumn{4}{c}{ CLUSTERS } \\
\cline { 2 - 5 } & $\mathbf{1}$ & $\mathbf{2}$ & $\mathbf{3}$ & $\mathbf{4}$ \\
\hline Precipitação & 37,938 & 0,154 & 3,274 & 0,749 \\
Temperatura Média Compensada & 21,517 & 23,424 & 20,413 & 21,713 \\
Temperatura Mínima & 18,317 & 16,872 & 16,547 & 16,252 \\
Temperatura Máxima & 26,518 & 31,075 & 26,386 & 28,870 \\
Evaporação & 2,032 & 6,810 & 2,696 & 4,064 \\
Umidade Relativa do Ar & 86,646 & 51,940 & 84,894 & 69,887 \\
\hline
\end{tabular}

Em seguida foi calculado o número de dias típicos identificados pelos clusters em cada estação meteorológica. A tabela 3 apresenta o resultado do cálculo em porcentagem de participação de cada cluster para cada estação. Nota-se que nenhuma estação se adequou ao cluster 1. Para definir a que cluster cada estação pertence primeiramente foram observadas e destacadas em verde na tabela 3 aquelas estações meteorológicas em que há $50 \%$ ou mais de dias típicos em um cluster, sendo ele o definido para tal estação. Foi observado que algumas estações possuíam entre 30 e 40\% dos dias em dois clusters diferentes. Para decidir a qual deles pertencia cada uma dessas estações, primeiramente foi elaborada a figura 3, para auxiliar na visualização dessa dualidade. 
Tabela 3: Porcentagem de participação dos clusters por estações meteorológica

\begin{tabular}{l|c|c|c|c}
\hline \multicolumn{1}{c|}{ ESTAÇÃO } & \multicolumn{4}{c}{ CLUSTER } \\
\cline { 2 - 5 } \multicolumn{1}{c|}{ METEOROLÓGICA } & $\begin{array}{c}\mathbf{1}(\boldsymbol{\%}) \\
\text { Count }\end{array}$ & $\begin{array}{c}\mathbf{2}(\boldsymbol{\%}) \\
\text { Count }\end{array}$ & $\begin{array}{c}\mathbf{3}(\boldsymbol{\%}) \\
\text { Count }\end{array}$ & $\begin{array}{c}\mathbf{4}(\boldsymbol{\%}) \\
\text { Count }\end{array}$ \\
\hline Araçuá Araxá & 3,0 & 50,2 & 11,0 & 35,8 \\
Bambui & 7,1 & 18,2 & 42,9 & 31,9 \\
Barbacena & 6,3 & 3,7 & 53,9 & 36,1 \\
Belo Horizonte & 6,2 & 4,9 & 60,6 & 28,2 \\
C. do Mato Dentro & 7,3 & 32,8 & 17,6 & 42,2 \\
Caparaó & 6,5 & 7,4 & 44,8 & 41,4 \\
Capinópolis & 5,6 & 1,4 & 54,9 & 38,1 \\
Caratinga & 6,3 & $27,25,4$ & 31,5 & 34,9 \\
Dimantina & 5,4 & 10,9 & 46,4 & 42,8 \\
Formoso & 6,4 & & 41,6 & 41,1 \\
Itamarandiba & 5,1 & & 20,5 & 31,8 \\
Ituiutaba* & 4,7 & 42,7 & 52,5 & 37,0 \\
João Pinheiro & 6,5 & 5,8 & 52,5 \\
Juiz de Fora Lavras & 6,2 & 25,0 & 23,4 & 45,1 \\
Machado & 7,6 & 36,2 & 20,6 & 37,0 \\
Monte Azul & 6,4 & 5,4 & 56,5 & 30,5 \\
Paracatu* & 6,9 & 14,6 & 31,9 & 47,1 \\
Patos de Minas & 3,3 & 10,6 & 41,3 & 41,3 \\
Pedra Azul & 6,5 & 58,5 & 11,0 & 27,1 \\
Pompéu & 6,9 & 23,1 & 22,9 & 47,5 \\
Salinas* & 3,8 & 26,6 & 27,7 & 38,8 \\
São Lourenço & 5,7 & 12,9 & 30,8 & 52,6 \\
Uberaba & 3,7 & 30,5 & 23,9 & 39,9 \\
Viçosa & 6,9 & $26,16,9$ & 27,1 & 43,2 \\
& 7,6 & 2,2 & 37,7 & 48,4 \\
& 5,6 & & 29,8 & 36,7 \\
& & & & 30,1 \\
\hline
\end{tabular}

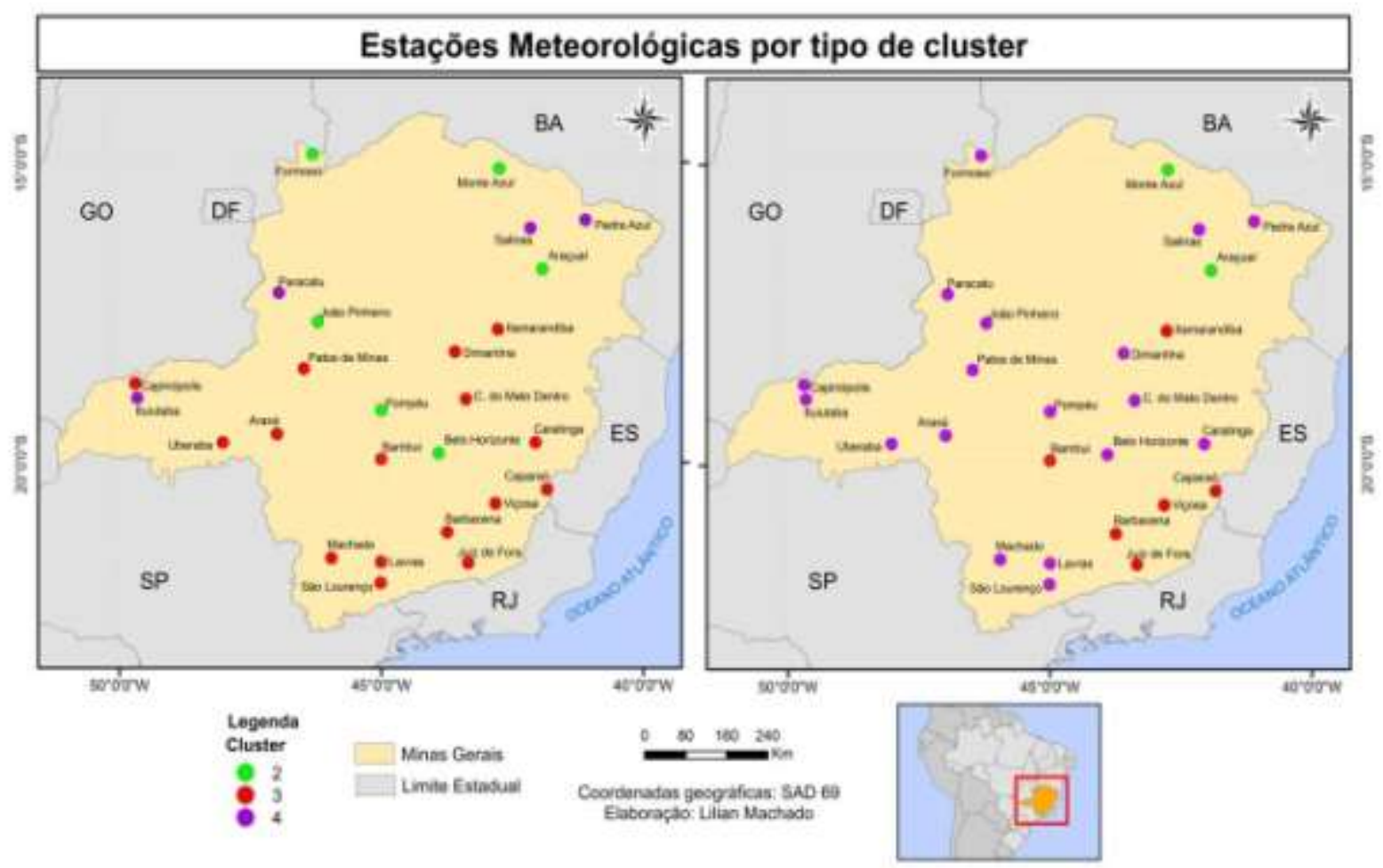

FIGURA 3: Localização das estações meteorológicas do INMET utilizadas no trabalho.

Cadernos do Leste 
Para decidir a que cluster pertencia cada estação foi observada a localização delas e comparado o comportamento médio anual das variáveis temperatura e precipitação da estação em questão e das estações mais próximas à ela, com o auxílio da figura 4. Além disso, foram calculadas as médias mensais das estações meteorológicas que se encaixavam em mais de um cluster e das estações mais próximas para fins de comparação entre elas. Para a elaboração da figura 4 foi calculada a média anual das varáveis temperatura e precipitação de 1981 a 2011 das estações meteorológicas utilizadas e plotadas no software ArcGis 10.1. Em seguida foram feitas interpolações dos dados. Para a variável temperatura utilizou-se o método interpolador Krigagem, o qual se adéqua melhor à espacialização do comportamento térmico por ser a temperatura uma variável contínua. Para a variável precipitação foi utilizado o método IDW (Inverse Distance Weighting), o qual considera, sobretudo, o comportamento das variáveis vizinhas, que deve ser semelhante ao da variável analisada. Como a chuva é um fenômeno de distribuição discreta, esse método de interpolação se adequou melhor à representação dos dados de precipitação média anual.

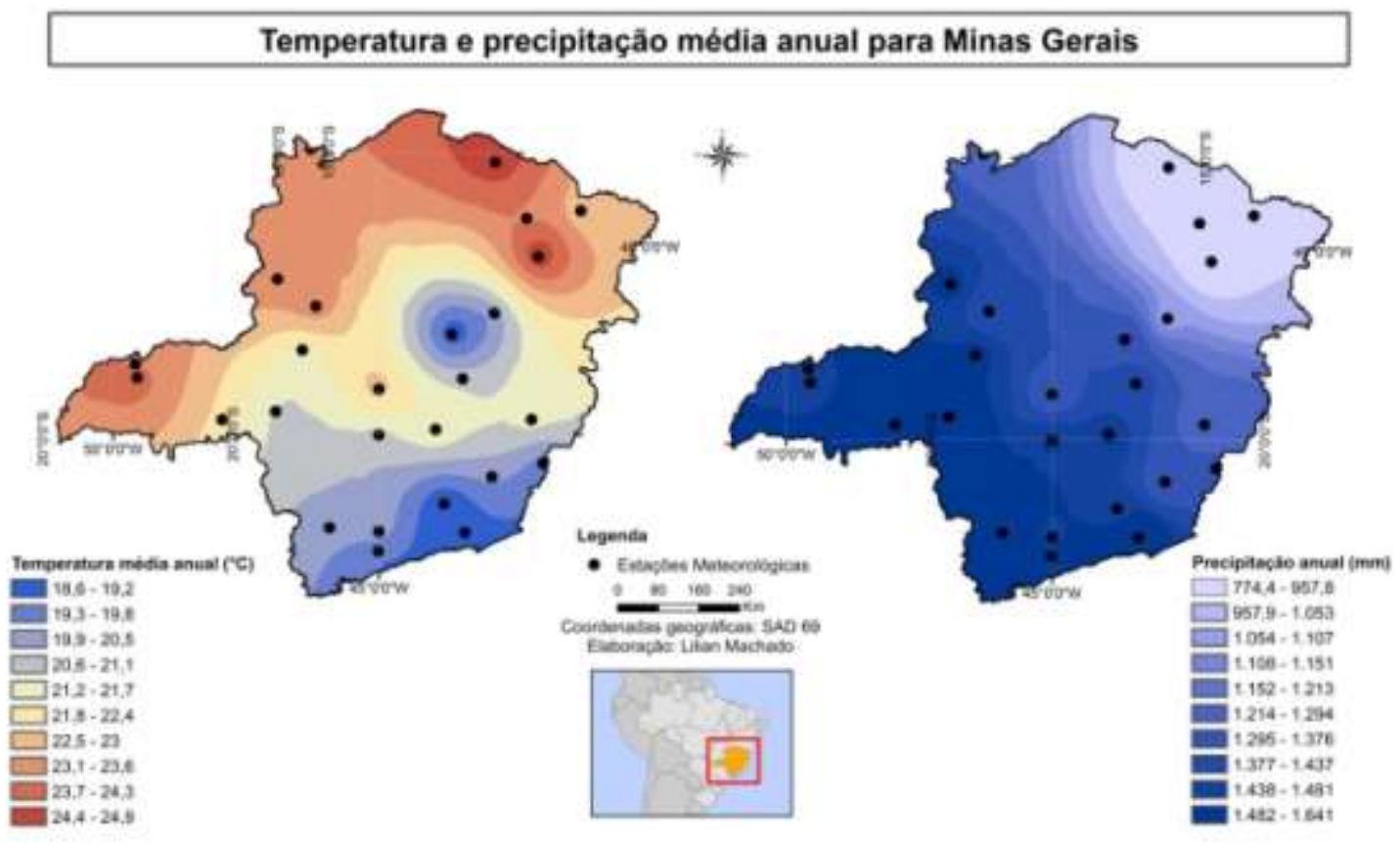

FIGURA 4: Distribuição da temperatura e precipitação média anual (1981-2011) para o estado de Minas Gerais.

As estações que se encaixavam em mais de um cluster foram então comparadas com o comportamento médio mensal e com a distribuição da temperatura média anual e a precipitação média anual (1981-2011) e encaixadas em um cluster. O cluster final para cada estação está representado na figura 5. 


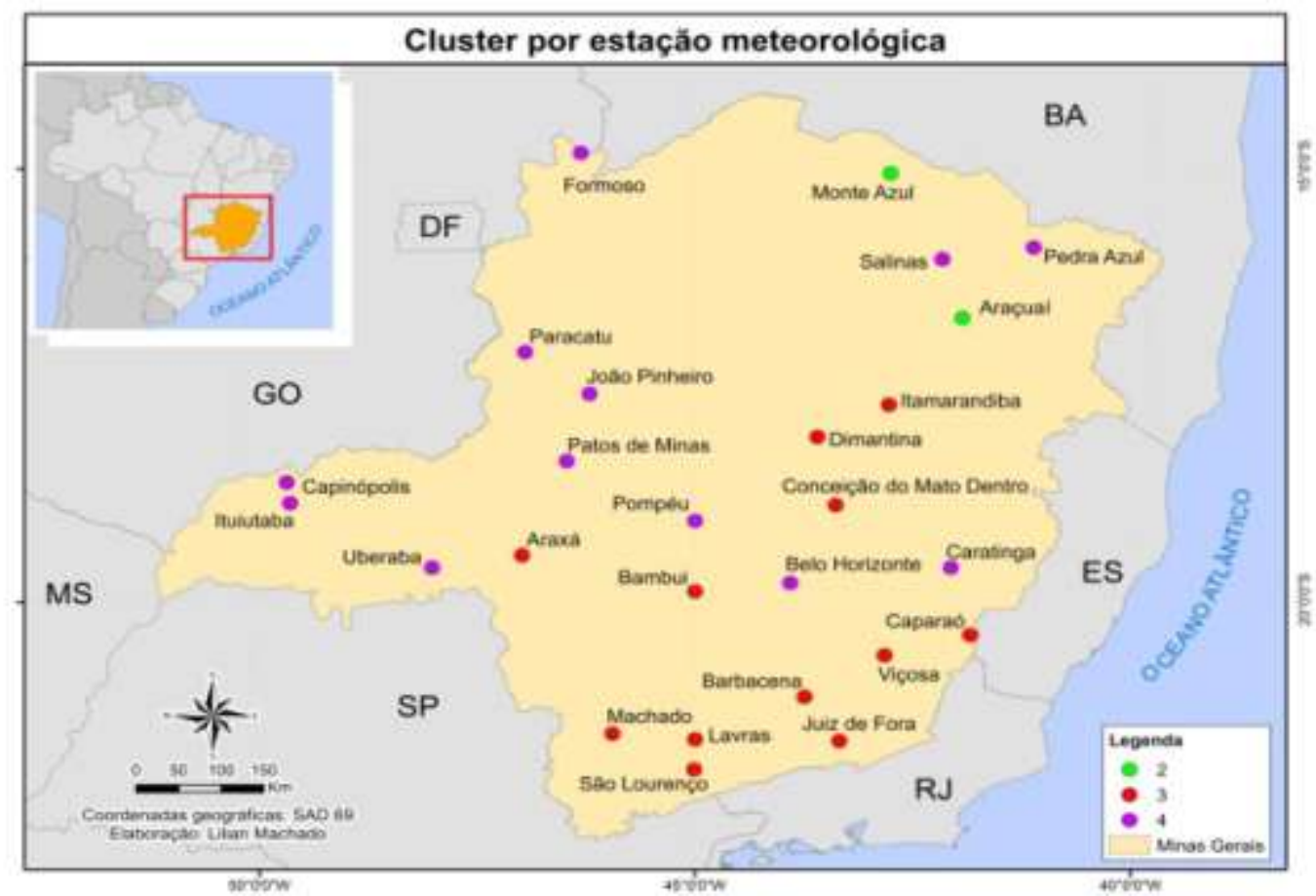

FIGURA 5: Cluster final definido por estação meteorológica.

Após definido o cluster para cada estação, foi necessário adotar uma nomenclatura que representasse o comportamento climático das localidades. Para isso, recorreu-se à literatura consultada. Dentre os trabalhos consultados e após verificar o comportamento médio mensal das estações meteorológicas para encaixá-las em cada cluster, aquele que melhor se adequou aos clusters definidos foi o trabalho de Nimer (1979a). Assim, foram atribuídas as seguintes nomenclaturas, adaptadas de Nimer (1979a) (TAB. 4):

Tabela 4: Nomenclatura definida para cada tipo climático

\begin{tabular}{|c|c|c|}
\hline CLUSTER & NOMENCLATURA & SIGNIFICADO \\
\hline 1 & \multicolumn{2}{|c|}{$\begin{array}{l}\text { Não foi definido um nome para este cluster já que nenhuma estação meteorológica se } \\
\text { adequou aos valores do mesmo. }\end{array}$} \\
\hline 2 & Quente e semi-árido & $\begin{array}{l}\text { Média térmica maior que } 18^{\circ} \mathrm{C} \text { em todos os meses e } \\
\text { meses secos que podem varias de } 6 \text { a } 7 \text { meses. }\end{array}$ \\
\hline 3 & Subquente e úmido & $\begin{array}{l}\text { Média térmica entre } 15 \text { e } 18^{\circ} \mathrm{C} \text { em pelo menos } 1 \text { mês do } \\
\text { ano e meses secos variando de } 1 \text { a } 3 \text { meses. }\end{array}$ \\
\hline 4 & Subquente e semi-úmido & $\begin{array}{l}\text { Média térmica entre } 15 \text { e } 18^{\circ} \mathrm{C} \text { em pelo menos } 1 \text { mês do } \\
\text { ano e meses secos variando de } 4 \text { a } 6 \text { meses. }\end{array}$ \\
\hline
\end{tabular}


Por fim, para delimitar as unidades climáticas foi utilizado como base um mapa topográfico do estado de Minas Gerais elaborado por meio das imagens SRTM (Shuttle Radar Topography Mission) disponibilizadas por pela Empresa Brasileira de Pesquisa Agropecuária $\left(\right.$ EMBRAPA $^{6}$ ), e os dados espacializados de temperatura e precipitação (FIG. 4). Para auxiliar a análise do mapa gerado, foram elaborados gráficos ombrotérmicos de duas cidades de cada tipo climático, utilizando-se a média mensal dos dados de temperatura e precipitação no período de 1981-2011.

\section{4- RESULTADOS E DISCUSSÃO}

O estado de Minas Gerais está inserido, na escala zonal, no Clima Tropical Brasil Central (IBGE, 2002). Segundo Nimer (1979a), neste se impõe o predomínio do Anticiclone Subtropical do Atlântico Sul (ASAS) ${ }^{7}$ e de pequenas altas continentais, com duas estações bem definidas: uma chuvosa e outra seca. $\mathrm{Na}$ estação seca o ASAS é o responsável por manter a estabilidade atmosférica. Na estação chuvosa há a formação de linhas de instabilidade (IT's) e da Zona de Convergência do Atlântico Sul (ZCAS), corredor de baixas de orientação NW-SE que se forma desde o litoral sudeste até o estado do Amazonas. A distinção entre verão e inverno, segundo Nimer (1979a), é reforçada pelo regime térmico uma vez que, excluindo-se as áreas montanhosas, o verão é quente em toda a região abrangida por este clima, em oposição ao inverno que é mais brando nas áreas mais ao sul e nas áreas serranas.

Em uma escala de abordagem regional, é possível perceber a expressão zonal descrita por Nimer (1979a), sobretudo no regime pluviométrico. As áreas de clima subquente e úmido (FIG. 6) estão localizadas mais ao sul do estado de Minas Gerais. Nesta região, os meses de seca não ultrapassam três, correspondendo aos meses de inverno, quando a atuação do ASAS é potencializada e este desloca seu centro de ação mais para sul.

Nota-se, na figura 6 que o clima subquente e úmido também abrange uma porção central do estado, compreendendo as estações metereológicas de Itamarandiba, Diamantina e Conceição do Mato Dentro. Estas, estão localizadas em áreas mais elevadas do domínio da Serra do Espinhaço, o que influi na precipitação orográfica e no regime térmico mais brandodo que os arredores. $\mathrm{Na}$ figura 7 estão representados os gráficos ombrotérmicos de duas cidades localizadas em cada tipo climático definido. É possível perceber que as cidades de Barbacena e Diamantina, localizadas no tipo climático subquente e úmido, embora apresentem diferenças no comportamento térmico e pluviométrico ao longo do ano, apresentam um regime semelhante. Ambas são caracterizadas por três meses secos, sendo eles os meses

\footnotetext{
${ }^{6}$ SRTM: http://www.relevobr.cnpm.embrapa.br/conteudo/infotec.htm

${ }^{7}$ Nimer (1979b) denomina o ASAS como anticiclone do Atlântico sul.

Cadernos do Leste

Artigos Cientificos

Belo Horizonte, Dez. Vol.14, n¹4, 2014
} 
de junho, julho e agosto, e o pico máximo de precipitação entre os meses de outubro e janeiro. São cidades de clima úmido, porém a precipitação é distribuída sobretudo nos meses de verão, em boa parte, pela formação da Zona de Convergência do Atlântico Sul e pela incursão de Frentes Polares (NIMER, 1979b).

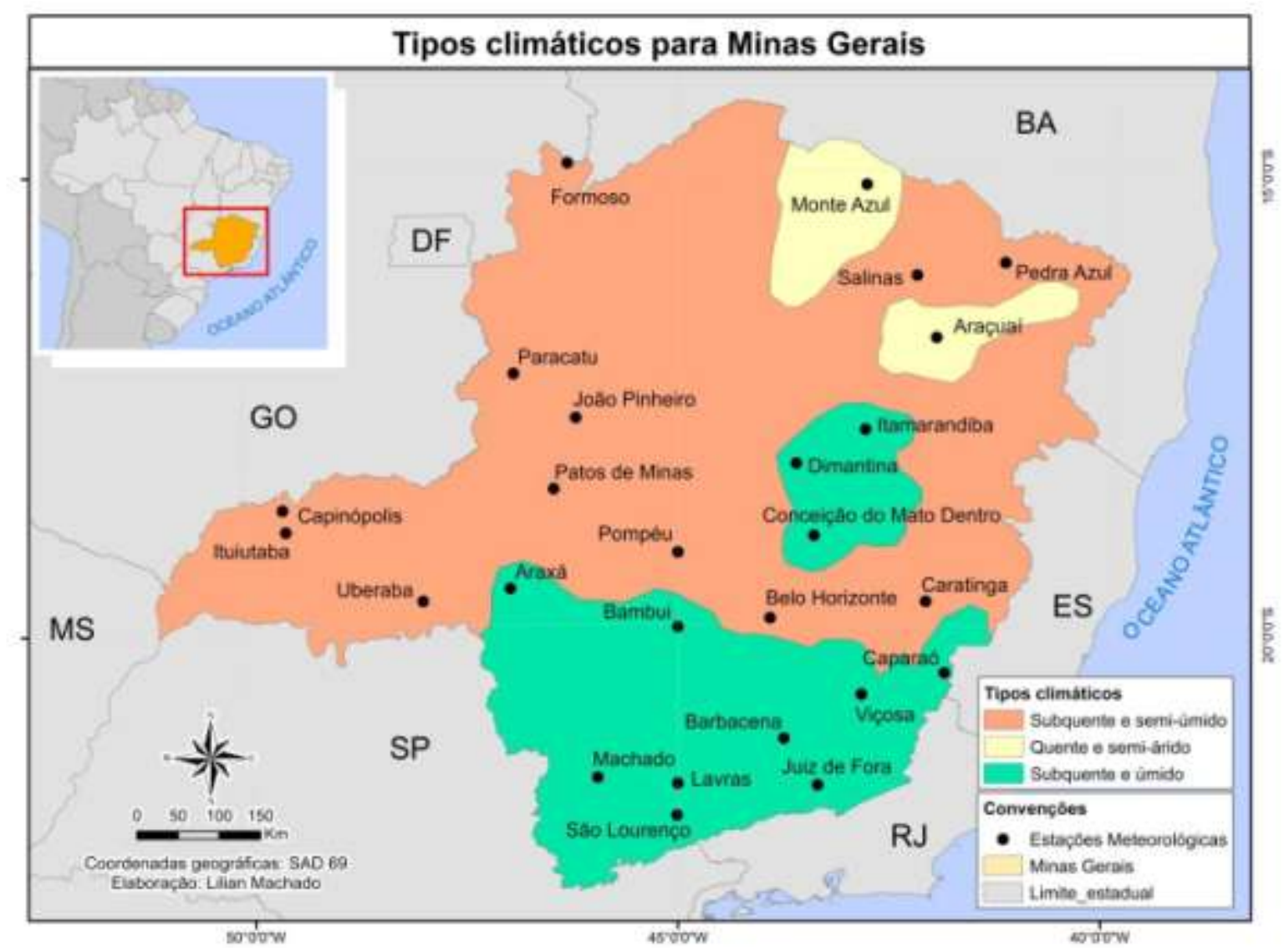

FIGURA 6: Tipos climáticos definidos para o estado de Minas Gerais.

As chuvas concentradas no verão são responsáveis, na região, por episódios de enchentes nas cidades na qual a ocupação urbana localiza-se em áreas de planícies fluviais, e movimentos de massa, inclusive com perdas humanas. A chuva concentrada em alguns meses do ano, aliada ao relevo movimentado e a formações geológicas em determinadas localidades que favorecem os deslizamentos, como as áreas em que predominam os xistos e os filitos no Quadrilátero Ferrífero, são fatores de risco para a população que ocupa encostas ou áreas de inundação fluvial. 
Clima Subquente e úmido

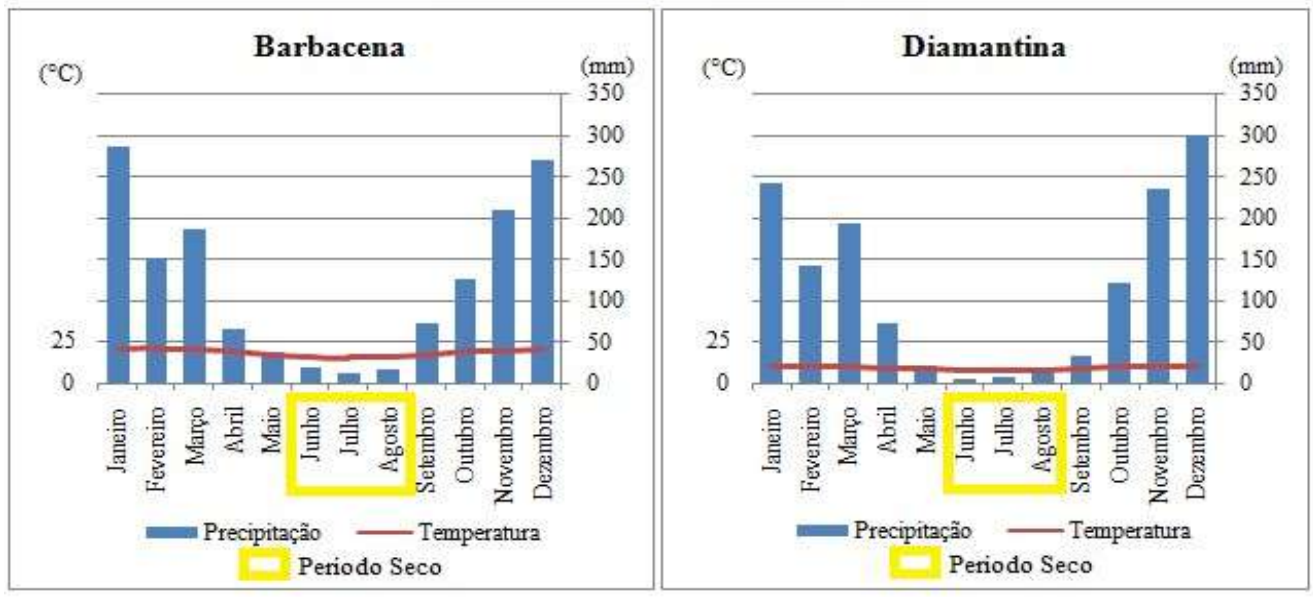

Clima Subquente e subúmido

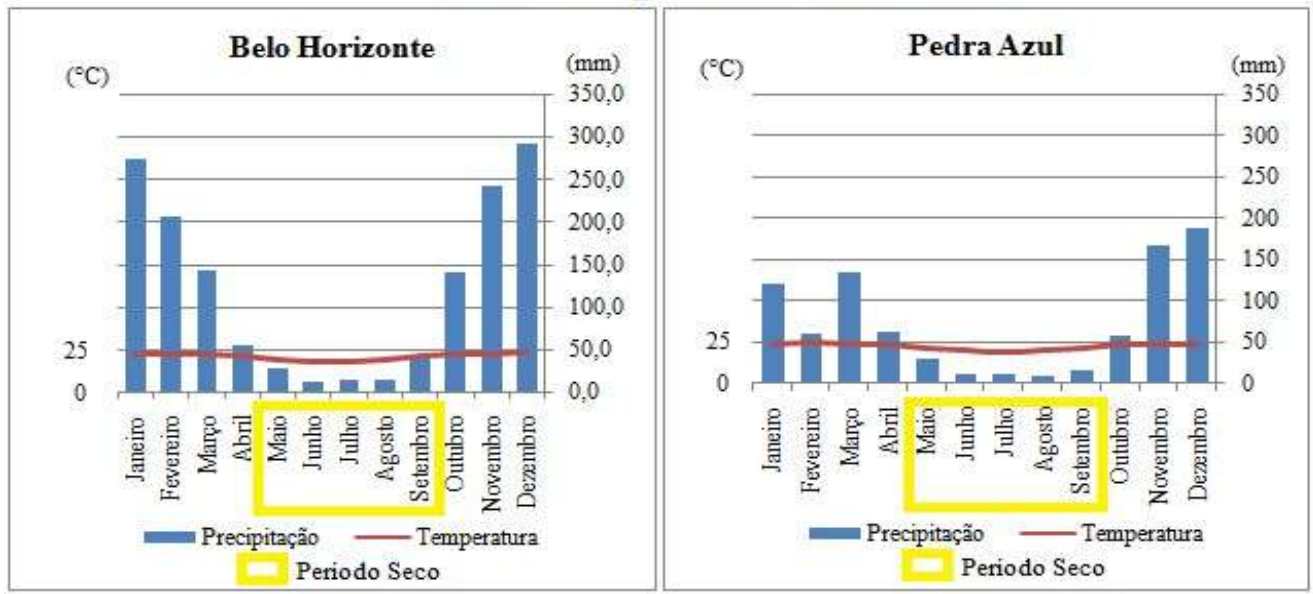

Clima Quente e semi-árido

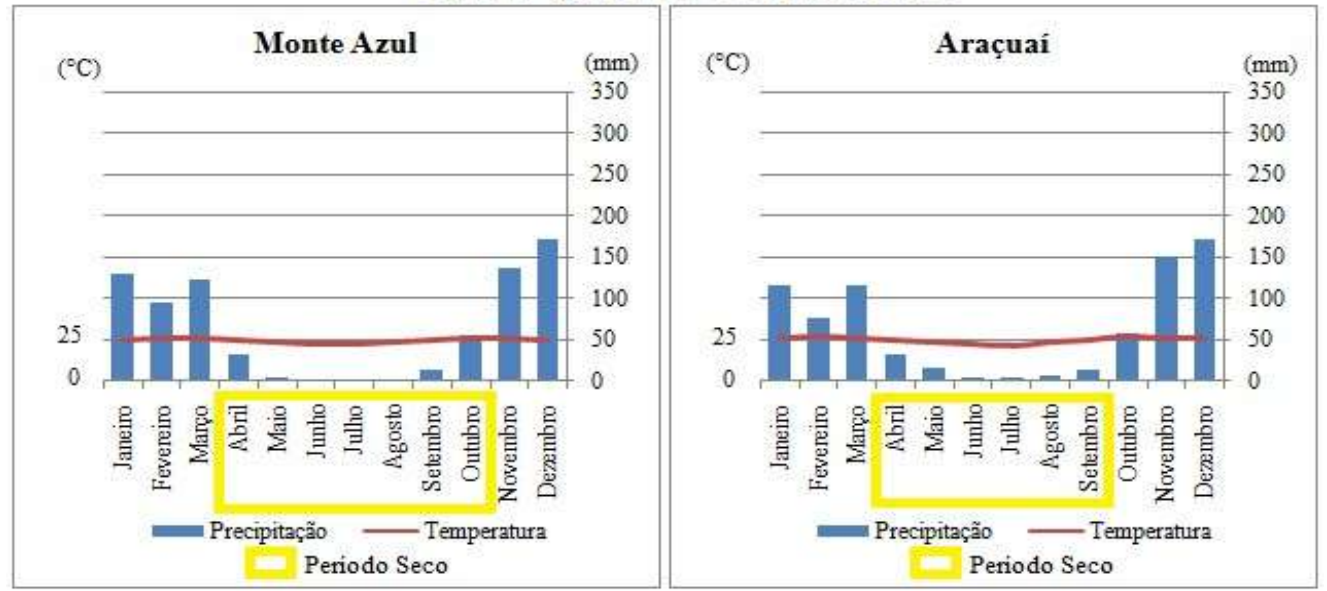

FIGURA 7: Gráficos ombrotérmicos.

A região de clima subquente e subúmido abrange a maior parte do estado cobrindo áreas da região central, oeste, norte, noroeste e nordeste de Minas Gerais (FIG. 6). Nestas regiões predominam um clima subquente com média próxima ou superior a $25^{\circ} \mathrm{C}$ nos meses mais quentes e média mínima

Cadernos do Leste 
nos meses de inverno que não alcança valores menores que $15^{\circ} \mathrm{C}$. Haja vista a extensa área que abrange este tipo climático, algumas diferenças são observadas entre as localidades. Isso fica visível ao se observar os gráficos ombrotérmicos das cidades de Belo Horizonte e Pedra Azul (FIG. 7). Embora ambas as cidades apresentem cinco meses secos correspondentes aos meses de maio a setembro, e pico chuvoso entre os meses de novembro e janeiro, o total pluviométrico para Belo Horizonte é expressivamente maior do que o de Pedra Azul, estando mais próximo ao das cidades localizada no triângulo mineiro do que as cidades localizadas mais ao norte, nordeste e noroeste do estado. Isso ocorre, em parte, devido às características de avanço das frentes frias sobre o território mineiro. Segundo Nimer (1979b) ao atingir a Região Sudeste as frentes frias, na maioria das vezes, já não possuem energia suficiente para manter a frontogênese. Dessa forma, a quantidade de chuva que chega às porções norte, nordeste e noroeste do estado são menores do que nas cidades localizadas na região central.

As regiões de clima quente e semi-árido, caracterizadas pela média térmica superior a $18^{\circ} \mathrm{C} \mathrm{em}$ todos os meses do ano e meses secos que variam de 6 a 7 meses, localizam-se na porção norte e nordeste do estado, compreendendo cidades localizadas no vale do rio Jequitinhonha e a depressão São Franciscana. Nestas localidades a escassez hídrica torna-se um problema paras as populações locais nos meses de seca, sobretudo para os pequenos produtores rurais. Nestas áreas há registro, inclusive, de migrações relacionadas à falta de emprego nas cidades e no meio rural devido à secas prolongadas em determinados anos (ESTADO DE MINAS, 2014). Nesta região predomina ventos de E e NE do ASAS, os quais somente desaparecem com a chegada de correntes de circulação perturbada provindas do Anticiclone Subpolar do Atlântico Sul ou por descontinuidades formadas no seio da massa de ar tropical que se aloja na região (Linhas de Instabilidade) (NIMER, 1979b). Por outro lado, a localização em latitudes mais baixas influencia as temperaturas médias mensais sempre acima dos $18^{\circ} \mathrm{C}$ potencializando a evapotranspiração, o que resulta na retirada de água do solo nos meses mais secos. Na figura 7 é possível observar o comportamento médio mensal da temperatura do ar e da precipitação nas cidades de Monte Azul e Araçuaí, localizadas na região. Fica claro o contraste pluviométrico destas cidades quando comparadas às demais apresentadas na figura 7.

\section{5- CONSIDERAÇÕES FINAIS}

A utilização da análise multivariada por meio do método de agrupamento não-hierárquico kmeans atendeu aos objetivos do trabalho de maneira satisfatória. No entanto, conforme destaca Neto 
(2004), convém lembrar que a análise multivariada, assim como qualquer outro conjunto de métodos estatísticos, padece dos mesmos problemas de toda a estatística. Segundo Neto (2004, p. 1)

\begin{abstract}
A estatística tem uma quasi-circularidade pouco explorada nos textos: pesquisamos para dizer algo significativo sobre o universo que elegemos, porém a pesquisa só será significativa se conhecermos suficientemente o universo para escolhermos adequadamente as variáveis e as condições de amostragem. A objetividade da pesquisa científica só começa depois da escolha das variáveis e das metodologias de análise, antes disto à atividade científica é completamente subjetiva.
\end{abstract}

Portanto, ainda que os procedimentos estatísticos aqui utilizados tenham cumprido a função metodológica proposta para se chegar aos resultados obtidos, cabe destacar que não se esgotam as possibilidades do ponto de vista matemático para gerar classificações climáticas. Os resultados apresentados são respostas aos métodos utilizados e ao objetivo proposto, sendo possível gerar inúmeras classificações climáticas para o estado de Minas Gerais diferenciadas com base em outros métodos estatísticos (ou não estatísticos) e outros objetivos.

Assim como o trabalho de Nimer (1979a), os resultados obtidos neste trabalho distinguiram três tipos climáticos. No entanto, Nimer (1979a) identificou diversas subdivisões para estes tipos climáticos relacionadas ao regime térmico-pluviométrico anual das localidades. Não foi pretendido neste trabalho alcançar o nível de detalhe obtido por Nimer (1979a) na elaboração do mapa de climas do Brasil. Ainda assim, os resultados demonstraram aspectos interessantes do comportamento climático no estado, como a distribuição pluviométrica discrepante, com regiões que recebem um total anual pluviométrico significativo, enquanto outras se enquadram em climas semi-áridos.

Comparando os resultados obtidos com o mapa gerado por Álvares et. al (2013) baseado na classificação de Köppen, é possível perceber a mesma relação entre relevo, pluviosidade e temperatura observada na localidade de Diamantina, Conceição do Mato Dentro e Itamarandiba, que destacam essa área, de relevo movimento e maiores altitudes, das áreas ao arredor.

Com relação aos efeitos climáticos sobre as atividades humanas no estado, é importante destacar que a região apresenta problemas ambientais enormes, sendo muitos deles desencadeados por condicionantes atmosféricas, especialmente precipitações concentradas. Nunes et al. (2009), reforça que tais problemas advêm da desconsideração das especificidades do meio físico, incluindo aí a natureza climática, e da ocupação do espaço comandada por uma lógica alheia aos componentes naturais. A concentração temporal das precipitações é um traço típico dos regimes climáticos tropicais úmidos e subúmidos e, portanto, inerente às áreas em que tais tipos climáticos predominam em Minas Gerais. No entanto, o que se assiste a cada ano é uma sucessão de tragédias como os escorregamentos de encostas 
e inundações urbanas que, certamente não são causadas pela chuva, porém são deflagradas por ela (NUNES et al., 2009).

Contrastando com esse quadro, o norte de Minas Gerais esteve à margem do crescimento econômico das demais áreas da Região Sudeste o que está, segundo Nunes et al. (2009), atrelado ao quadro físico e climático da área que não apresenta as condições ditas ideais para a lógica prevalecente do uso do espaço. Dessa forma, as áreas semi-áridas do estado sofrem com o descaso do investimento público que só vem a agravar as consequências das secas prolongadas, sobretudo no cotidiano da população menos favorecidas e dos pequenos produtores rurais.

A compreensão sobre as variadas condições de clima no estado de Minas Gerais devem servir de base para o planejamento territorial e econômico do estado. Uma vez que as características climáticas influem diretamente sobre as atividades humanas, compondo, inclusive, fatores de risco à ocupação, elas não devem passar despercebidas nos planos regionais e, principalmente, em escalas meso ou topoclimáticas, nos estudos de planos diretores municipais, os quais seriam os instrumentos mais efetivos para se evitar as tragédias deflagradas nas chuvas de verão e mitigar os impactos econômicos e sociais em períodos de seca, mesmo nas áreas de tipos climáticos subúmidos.

\section{REFERÊNCIAS BIBLIOGRÁFICAS}

ALVARES, C. A.; STAPE, J. L.; SENTELHAS, P. C.; GONÇALVES, J. L. M.; SPAROVEK, G. Köppen's climate classification map for Brazil. Meteorologische Zeitschrift, v. 22, n. 6, p. 711-728, 2013.

ANDRÉ, R. G. B.; MARQUES, V. S.; PINHEIRO, F. M. A.; FERRAUDO, A. S. Identificação de regiões pluviometricamente homogêneas no estado do Rio de Janeiro, utilizando-se valores mensais. Revista Brasileira de Meteorologia, v. 23, n. 4, p. 501-509, 2008.

AYOADE, J. O. Introdução à climatologia para os trópicos. $3^{\mathrm{a}}$.ed. Rio de Janeiro: Bertrand, Brasil, $1991.332 \mathrm{p}$.

BARRY, R. G.; CHORLEY, R. J. Atmosfera, tempo e clima. $8^{a}$ Ed. Porte Alegre: Bookman, 2013. 512 p.

BECKER, C. T.; BRAGA, C. C.; CEBALLOS, J. C. Regionalização da precipitação e temperatura no estado do Rio Grande do Sul a partir de análise de agrupamentos. In: Anais...Congresso Brasileiro de Meteorologia, São Paulo, v. 1, p. 255-232, 1992.

DOURADO, C. S. ;AVILA,A.M.H.;OLIVEIRA,S.R.M.. Regionalização da Precipitação no Estado da Bahia por meio de Técnicas de Mineração de Dados. In: Anais...XVII Congresso Brasileiro de Meteorologia, Gramado (RS), 2012. Disponível em: <http://www.sbmet.org.br/cbmet2012/pdfs/64RH.pdf>. Acesso em: 15 de nov. de 2014. 
Minas e no Vale do Jequitinhonha. 2014. Disponível em: < ESTADO DE MINAS. Jornal Estado de Minas on line. Falta água para viver no Norte de http://www.em.com.br/app/noticia/economia/2014/07/25/internas_economia,551696/faltaaguapara-viver-no-norte-de-minas-e-no-vale-do-jequitinhonha.shtml>. Acesso em: 23 de nov. de 2014.

FERREIRA, C. C. M. Aplicação da lógica nebulosa (Fuzzy Cluster) na definição de umidades climáticas: estudo de caso na bacia do rio Paraibuna - MG/RJ. Revista Brasileira de Climatologia, ano 8, vol. 10, p. 85-97, 2012.

GUEDES, R. V. S.; LIMA, F. J. L.; AMANAJÁS, J. C.; BRAGA, C. C. Análise em componentes principais da precipitação pluvial no estado do Piauí e agrupamento pelo método de Ward. Revista de Geografia da Universidade Federal de Pernambuco, v. 27, n. 1, 2010.

INSTITUTO BRASILEIRO DE GEOGRAFIA. Mapa Clima do Brasil. Escala 1: 5.000.000. Rio de Janeiro: IBGE. 2002.

INTITUTO SUPERIOR DE AGRONOMIA - I.S.A. Análises Classificatórias. In: I.S.A; Estatística Multivariada. Lisboa, p. 117 - 140, 2009. Disponível em: $<$ http://www.isa.utl.pt/dm/mestrado/mmacb/UCs/em/webEMCap4.pdf $>$. Acesso em: 14 de nov. de 2014.

MACQUEEN, J. Some methods for classification and analysis of multivariate observations. In: Proceedings of the Fifth Berkeley Symposium on Mathematical Statistics and Probability. Berkeley (California), p. 281-297, 1967. Disponível em:

<http://projecteuclid.org/euclid.bsmsp/1200512992>. Acesso em: 14 de nov. de 2014.

MENDONÇA, F.; DANNI-OLIVEIRA, I. M. Climatologia: noções básicas e clima do Brasil. São Paulo: Oficina de Textos, 206 p., 2007.

NETO, J. M. M. Estatística multivariada: uma visão didática-metodológica. Revista Filosofia da Ciência, 13p., 2004. Disponível em: < http://www.criticanarede.com/cien_estatistica.html >. Acesso em: 16 de nov. de 2014.

NIMER, E. Um modelo metodológico de classificação de climas. Revista Brasileira de Geografia, v. 41, p. 59-89, 1979a.

NIMER, E. Climatologia do Brasil. Rio de Janeiro: IBGE, 1979 b. 421p.

NUNES, L. H.; VICENTE. A. K.; CANDIDO, D. H. Clima da região sudeste do Brasil. In: CAVALCANTI, I. F. A.; FERREIRA, N. J.; SILVA, M. G. A. J.; SIAS, M. A. F. S. (Org.). Tempo e Clima no Brasil, São Paulo: Oficina de Textos, p. 243-258, 2009. 